\title{
Leverage and Risk Taking under Moral Hazard
}

\section{Christian Hott ${ }^{1}$}

Received: 26 July 2019 / Revised: 25 May 2021 / Accepted: 5 June 2021 /

Published online: 25 June 2021

(C) The Author(s) 2021

\begin{abstract}
In this paper, I analyze the effectiveness of different capital regulations in mitigating the effects of moral hazard that exists only for systemically important banks. Leverage restrictions have the potential to reduce the fraction of banks that are systemically important but do not mitigate moral hazard for those that are. Risk adjusted requirements could mitigate moral hazard (of banks with low leverage) but do not affect (endogenous) systemic risk. A combination of both requirements as proposed by the Basel III framework can be successful, although only under restrictive conditions.
\end{abstract}

Keywords Capital regulation · Moral hazard · Leverage

JEL Classification G21 · G28

\section{Introduction}

Forty years ago, Koehn and Santomero (1980, p. 1235) wrote:

Recent large bank failures ..., coupled with an unstable economic environment, have rekindled the controversy over the adequacy of bank capital. There is, of course, an abundance of literature on both sides of the bank capital issue.

These sentences still apply. The excessive leverage and risk-taking of many financial institutions led to the global financial crisis. As a reaction, "The Basel III framework introduced a simple, transparent, non-risk based leverage ratio to act as a credible supplementary measure to the risk-based capital requirements". ${ }^{1}$ However, there is still no agreement on the effectiveness of tighter capital regulations in reducing the risks to financial stability.

A reason for excessive leverage and risk-taking and, hence, for the need for capital regulation is the existence of moral hazard in the banking sector. ${ }^{2}$ The goal of this paper is to

\footnotetext{
${ }^{1}$ Basel Committee on Banking Supervision (2014, p. 1).

${ }^{2}$ Other reasons for excessive leverage and risk taking in the recent crisis were bad risk management and poor information about some new products. See, e.g., Alexander and Baptista (2017); Hott (2015).

$\bowtie$ Christian Hott

hottc@hsu-hh.de
}

1 Helmut-Schmidt-University Hamburg, Holstenhofweg 85, 22043 Hamburg, Germany 
analyze the effects of moral hazard on the leverage and risk-taking of banks as well as to evaluate the success of different capital requirements in mitigating adverse effects.

The theoretical literature is sharply divided about the impact of tighter capital requirements on financial stability because of different assumptions about market imperfections (e.g., the specific form of deposit insurance or government guarantees), about the behavior of banks, and about details of capital requirements. ${ }^{3}$

Models that find that tighter capital requirements improve financial stability include, for example, Rochet (1992) and Kim and Santomero (1988). Both papers look at a banking sector with deposit insurance and find that tighter requirements limit risk-taking as banks with more capital put more capital at risk. ${ }^{4}$ While Kim and Santomero assume fixed-rate deposit insurance and find that a leverage restriction is sufficient, Rochet assumes riskbased deposit insurance premiums and finds that risk-based capital requirements are needed. $\mathrm{Wu}$ and Zhao (2016) conclude that both types of capital requirements are needed to limit misreporting. Furlong and Keeley (1989) find that tighter leverage restrictions can mitigate the effects of moral hazard.

In contrast, models which consider the disciplining effect of depositors, such as Calomiris and Kahn (1991) and Ashcraft (2008), typically find that banks with higher leverage take less risk. Koehn and Santomero (1980) find that banks react to tighter requirements by increasing risk, but their paper does not include risk-based requirements. Furthermore, their paper only looks at the effect on the default probability of banks without considering the loss that creditors suffer in the event of default. Other models, such as Kiema and Jokivuolle (2014), allow for diversity among banks and find that tighter requirements for the leverage ratio increase risk only for low-risk banks but make the system's banks more similar and thus increase systemic risk. Blum (1999) considers flows as well as stocks. He finds that when retained earnings increase capital, then tighter requirements might increase risk-taking because earnings increase. ${ }^{5}$

This paper presents a model which combines the aforementioned ingredients to adequately capture the relationship of capital requirements with risk-taking and financial stability. In addition to (implicit) guarantees and leverage ratio and risk-based capital requirements, the model includes endogenous behavior and limited liability of banks, a disciplining effect of deposits, and the expected losses imposed on bank creditors rather than just probabilities of bank failure. Thus, a bank must not only optimize the riskiness of its assets but also its leverage. While other papers capture some of these ingredients, the model in this paper incorporates all of them. ${ }^{6}$

First, I develop a benchmark model without any banking regulation in which I assume that a monopolistic bank has limited liability but is disciplined by perfectly informed depositors. I show that the expected losses of depositors may increase or decrease with leverage because of a negative relation between risk-taking and the leverage of a bank. Expected

\footnotetext{
${ }^{3}$ VanHoose (2007) provides a good overview of the theoretical literature on this issue.

${ }^{4}$ This effect of regulation on risk taking is also demonstrated by Behr et al. (2010). Like Kim and Santomero, however, their model does not consider the disciplining effect of depositors.

${ }^{5}$ Somewhat related, tighter capital requirements lower bank profits per share and the value of surviving, so risk-taking may increase (see also Schliephake, 2016).

${ }^{6}$ Papers like Berger et al. (2008) and Harding et al. (2013) analyse the effect of a bank's franchise value (i.e. the value of surviving) on its optimal capital ratios and risk taking. This aspect is not within the scope of my model.
} 
losses can be zero if the leverage is high but the risk is zero, or zero if the risk is very high and the leverage is one (no deposits). Between these two extremes there is a maximum of expected losses.

Next, I introduce moral hazard by assuming that there is a positive probability that the government will bail out the bank if it is systemically important and becomes insolvent. As a result, the disciplining effect of deposits is reduced and the bank takes more asset risk, which leads to higher aggregated expected losses for depositors and the government. A leverage restriction could reduce bank size and therefore fewer banks would be subject to moral hazard, but a leverage restriction does not alter the moral hazard for banks that remain systemically important. A risk-adjusted capital requirement has the potential to mitigate moral hazard but does not reduce the number of systemically important banks. Under very restrictive conditions an optimal combination of leverage and risk-based requirements can be successful.

A major contribution of this paper is that it showcases the weaknesses and fragility of different capital regulations. In particular, an optimal regulation requires both a risk-weighted and an unweighted capital requirement. Moreover, this optimal mix strongly depends on the nature of the banking sector, so in a world of heterogeneous banks, details of requirements would have to vary with bank characteristics.

The paper proceeds as follows: Section 2 presents the baseline model. Section 3 explores the effects of moral hazard. Section 4 presents an evaluation of the effects of different capital requirements on bank behavior and on financial stability. Section 5 summarizes offers concluding remarks.

\section{The benchmark model}

In this section, I develop a two-period model of an undistorted banking sector that serves as a benchmark for the analyses of the effects of moral hazard and the efficiency of regulation. It is a partial equilibrium model. Therefore, it does not allow for a welfare analysis of the different regulatory measures, as for example in Van den Heuvel (2008), Begenau (2020), or Clerc et al. (2015). However, the model enables me to compare market outcomes with and without moral hazard and to evaluate different policy measures with regard to their success in mitigating the distorting effects of moral hazard.

There are two periods, three types of assets, and two sectors. The three types of assets are a safe asset (money), risky bonds, and deposits. There is an unregulated monopolistic bank that exclusively invests in the bond market and finances its investments via its own capital and deposits. In the first period, the bank chooses the riskiness (default probability) of its bond portfolio as well as its leverage in order to maximize its profits in the second period. The second sector is formed by the depositors. Depositors decide how much of their wealth they want to consume in the first period, how much they want to hold as money, and how much they want to lend to the monopolistic bank.

\subsection{Basic assumptions}

\subsubsection{Safe asset}

The supply of the safe asset is completely elastic, and it pays zero interest rate. Therefore, the safe asset can be interpreted as money in a world without inflation. 


\subsubsection{Risky asset}

There is a continuum of bonds (or bond portfolios) with default probabilities $0<\pi<1 / 2$. In the first period the market price of the bond with the default probability $\pi$ is $P(\pi)$. In the second period, the pay-off of each bond is one if it does not default and zero if it defaults. The expected return $E\left(R_{t+1}(\pi)\right)$ of a bond is:

$$
E\left(R_{t+1}(\pi)\right)=(1-\pi) \frac{1}{P(\pi)} .
$$

I assume that there is a risk premium on the bond and that $P<1-\pi$. As demonstrated in the Appendix, I can reasonably assume that:

$$
P^{\prime}(\pi) \geq-\frac{P(1-P)}{\pi(1-\pi)} .
$$

\subsubsection{Deposits}

The market clearing interest rate on deposits is $r$. If the bank defaults, all its remaining assets are transferred to its depositors.

\subsubsection{The bank}

The monopolistic bank is assumed to be risk neutral and to maximize its expected profits $[E(Y)]$ by choosing optimal levels of asset risk and leverage. It invests in a single bond and finances its investment with its own capital and deposits.

In the first period the amount of capital of the bank is $C$ and its demand for deposits is $(f-1) C$. Hence, $f$ is the leverage of the bank and $f C$ are its total assets. The bank can also influence the default probability of its bond investments. However, lowering the default probability creates search costs and costs for financial engineering (or costs for monitoring in the case of loans). The corresponding cost function is $k(\pi)>0$ in which $k^{\prime}<0, k^{\prime \prime}>0$, and $k(0) \rightarrow \infty$.

In the second period the bank has to repay its deposits plus interest $(r)$. The expected return on its investment is given by Eq. 1 . I assume that the optimal leverage $f$ is larger than one and that the bank, therefore, becomes insolvent if the bond defaults. Therefore, the expected profits of the bank are:

$$
E(Y)=(1-\pi)\left[f \frac{1}{P}-(f-1)(1+r)\right] C-k(\pi) .
$$

Since the bank acts as a monopolist, it considers the influence of its decisions on the interest rate $(r)$.

\subsubsection{Depositors}

There are $N$ identical households that are assumed to exist for two periods. Each household is endowed with an initial wealth $w(W=N w)$ and maximizes its expected utility from consumption in the first and the second periods by choosing how much it saves $(i)$ and how it invests the savings. Households are assumed to have a standard logarithmic utility function and perfect information about the default probability of the bank $(\pi)$. Consumption in the first period is equal to the initial wealth minus savings $\left(c_{1}=w-i\right)$. Consumption in the second period depends on the return on the invested savings. Households are depositors 
and invest the fraction $\phi(0 \leq \phi \leq 1)$ of their savings in deposits and the rest $(1-\phi)$ in the safe asset (money). If the bank is solvent in the second period (probability: $1-\pi)$, then the return for the depositor $\left(R^{h}\right)$ is:

$$
R^{h}=\phi(1+r)+(1-\phi)=1+\phi r
$$

and if the bank defaults (probability: $\pi$ ), then it is:

$$
R^{l}=1-\phi .
$$

Hence, the maximization problem of the depositors is given by:

$$
E U=\ln (w-i)+\delta \pi \ln [(1-\phi) i]+\delta(1-\pi) \ln [(1+\phi r) i],
$$

where $\delta$ is the discount factor. Maximization leads to the following optimal savings $i$ and the optimal investment fraction $\phi$ :

$$
\begin{gathered}
i=\frac{\delta}{1+\delta} w \\
\phi=1-\pi \frac{1+r}{r} .
\end{gathered}
$$

Thus, the optimal savings rate is independent of the interest rate and the riskiness of deposits. However, the fraction of the savings that is invested into deposits $(\phi)$ depends positively on the interest rate $r$ and negatively on the default probability $\pi$. The aggregated supply of deposits is given by:

$$
\phi I=\left[1-\pi \frac{1+r}{r}\right] I,
$$

where $I=N i$.

\subsection{Equilibrium}

\subsubsection{Optimal leverage}

Since I have assumed that the bank acts as a monopolist in the market for deposits, I also assume that it considers the effects of its decisions on the price in this market: the interest rate $r$. Following Section 2.1.4, the bank's demand for deposits is $(f-1) C$; and following Section 2.1 .5 , the aggregated supply is $\phi I$. In equilibrium the demand has to be equal to the supply, therefore:

$$
(f-1) C=\phi I=\left[1-\pi \frac{1+r}{r}\right] I .
$$

With this equation, I can calculate the interest rate that depends on the leverage of the bank:

$$
r=\frac{\pi I}{(1-\pi) I-(f-1) C} \text {. }
$$

Since the risk-free interest rate is zero, $r$ can also be interpreted as the risk premium the bank has to pay. Following Eq. 11, this risk premium depends positively on the risk-taking $(\pi)$ and the leverage $(f)$ of the bank.

Following Section 2.1.4, the bank maximizes its expected income. Replacing the interest rate $r$ in Eq. 3 with its equilibrium value (11) yields the following equation:

$$
E(Y)=(1-\pi)\left[f \frac{1}{P}-(f-1)-\frac{(f-1) \pi I}{(1-\pi) I-(f-1) C}\right] C-k(\pi) .
$$


The profit maximizing leverage is given by:

$$
f=1+\frac{I}{C}(1-\pi)\left[1-\sqrt{\frac{\pi P}{(1-P)(1-\pi)}}\right] .
$$

Since I have assumed that there is a risk premium on the bond $(P<1-\pi)$, the term under the square root is smaller than one. Hence, the optimal leverage depends positively on the fraction $I / C$ and is always greater than one. Furthermore, since $\pi>0$, the optimal leverage is always smaller than $I / C+1$ that means depositors invest all their investments $I$ in deposits. Equation 13 also depends on the default probability $(\pi)$ and the corresponding bond price $P(\pi)$. This default probability is simultaneously chosen by the bank and hence is an endogenous variable. Nevertheless, as regulatory measures to address moral hazard (see Section 4) aim to influence leverage and/or risk-taking, the relation between the two variables will become important.

Proposition 1 For the monopolistic bank with perfectly informed depositors, there is a negative relation between optimal leverage $(f)$ and asset risk $(\pi)$.

\section{Proof See below.}

The direct effect of the default probability $(\pi)$ on optimal leverage is negative. However, the optimal leverage also depends negatively on the bond price $(P)$ that in turn depends negatively on the default probability. Hence, there is a positive, indirect effect from the default probability on the optimal leverage. In order to see whether the direct or indirect effect is stronger, the derivative of Eq. 13 with respect to $\pi$ is considered:

$$
\begin{aligned}
\frac{\partial f}{\partial \pi}= & -\frac{I}{C}\left[1-\sqrt{\frac{\pi P}{(1-P)(1-\pi)}}\right] \\
& -\frac{1-\pi}{2} \frac{I}{C} \frac{P^{\prime} \pi(1-\pi)+P(1-P)}{(1-P)^{2}(1-\pi)^{2}} \sqrt{\frac{(1-P)(1-\pi)}{\pi P}} .
\end{aligned}
$$

This derivative is negative if:

$$
-P^{\prime}<\frac{P(1-P)}{\pi(1-\pi)}+2 \frac{(1-P) P}{1-\pi}\left[\sqrt{\frac{(1-P)(1-\pi)}{\pi P}}-1\right] .
$$

Following Eq. 2, $-P^{\prime}$ is smaller than the first fraction on the right-hand side; since there is a risk premium on the bond $(P<1-\pi)$, the term in brackets is positive.

Hence, the derivative of the leverage $(f)$ with respect to the asset risk $(\pi)$ is negative and Proposition 1 is proven.

Proposition 2 For the monopolistic bank with perfectly informed depositors, there is a negative relation between leverage $(f)$ and the risk premium it has to pay $(r)$.

Proof See below.

Equation 11 shows that the direct effect of leverage on the interest rate is positive. However, there is also an indirect effect via risk-taking $(\pi)$. Equation 13 indicates that leverage depends negatively on $\pi$. Therefore, higher leverage comes with lower risk-taking, and 
this level has a negative effect on $r$. When we replace leverage with its optimum given by Eq. 13, the indirect effect becomes stronger and the interest rate depends positively on $\pi$, and therefore negatively on the leverage $f$ of the bank:

$$
r=\sqrt{\frac{\pi(1-P)}{(1-\pi) P}} .
$$

Hence, Proposition 2 is proven.

This negative relation between leverage and the risk premium is the result of the disciplining effect of deposits in combination with perfect information. An additional reason is that due to the payout structure of the risky bond, the bank's leverage has no direct effect on its probability of default. In a dynamic setting, a bank that has a higher leverage as a result of losses likely has to pay a higher risk premium. In my model, however, the bank actively chooses its leverage and, all other things equal, reacts to a higher risk premium by choosing lower leverage.

As mentioned in the introduction, existing papers highlight different aspects of the relationship between leverage and risk and would therefore also come to different conclusions when it comes to the link between leverage and risk premiums. Bernanke et al. (1999) look at the link between leverage and risk premiums in general. They argue that there should be a negative relationship between the risk premium and net worth (or capital level) as borrowers with little equity (high leverage) at risk create higher monitoring costs for the lender. However, the authors do not consider that borrowers change the riskiness of their investments and therefore the disciplining effect of debt.

There are also papers that argue that there should be a negative link between leverage and risk premiums. In Geanakoplos (2010) and Bhattacharya et al. (2015), for example, waves of optimism simultaneously lower risk premiums and inflate leverage and therefore create this negative relationship. Also Boissay et al. (2016) argue that bank balance sheets are pro-cyclical and that increasing leverage is coupled with decreasing risk premiums on the interbank market.

\subsubsection{Optimal risk-taking}

Besides choosing the optimal leverage for a given risk, the bank simultaneously chooses the profit maximizing default probability $\pi$ of its bond portfolio. By replacing the leverage $f$ with its optimal value (13) and the interest rate $r$ with Eq. 16, the expected profit Eq. 3 can be rewritten as:

$$
E(Y)=\frac{1-\pi}{P} C+\frac{1-\pi}{P} I[1-P-\pi+2 P \pi-2 \sqrt{\pi(1-\pi) P(1-P)}]-k(\pi) .
$$

Thus, the expected profits depend negatively on $\pi$. However, they also depend negatively on the bond price $P(\pi)$ and $k(\pi)$ that both depend negatively on $\pi$. Whether the negative direct or the positive indirect effect dominates and, hence, whether and at which level there is a profit maximizing risk $\pi$ depends on the effect of $\pi$ on $P$ and $k$. For illustration, I assume the following price and cost functions ${ }^{7}$ :

$$
\begin{gathered}
P(\pi)=1-\sqrt{\pi}, \\
k(\pi)=\frac{0.01}{\pi} .
\end{gathered}
$$

\footnotetext{
${ }^{7}$ For a motivation of the price function, please see Appendix.
} 


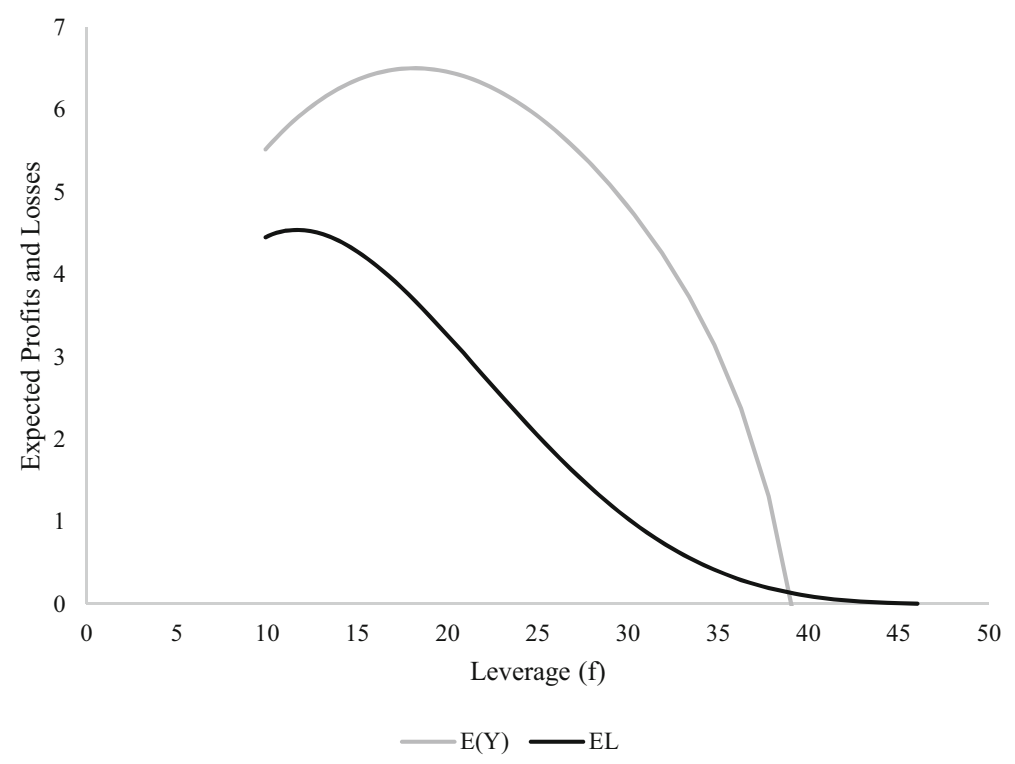

Fig. 1 Relation of leverage and the expected profits $E(Y)$ of the bank and the expected losses for depositors EL. $P(\pi)=1-\sqrt{\pi}, I=50, C=1$ and $k(\pi)=0.01 / \pi$

If the two remaining parameters are $C=1$ and $I=50$, profit is maximized at a $\pi$ of 0.21 . The cost function makes a low default probability less attractive. For higher costs of $k(\pi)=0.05 / \pi$, the optimal default probability increases to 0.23 . With regard to the parameters $C$ and $I$, their relative size matters more than their absolute levels. For $C=100$ and $I=10.000$, the optimal $\pi$ is still at 0.21 . For a relatively high level of $I=1.000$ (compared to $C=1$ ), the optimal $\pi$ decreases to 0.18 .

According to Eq. 13, the initial example $(C=1, I=50$, and $k(\pi)=0.01 / \pi)$ with an optimum of $\pi=0.21$ translates into an optimal leverage of 18 . Figure 1 shows the corresponding dependence of the expected profit on the leverage of the bank. It increases with leverage until the decreasing bond returns and increasing costs for financial engineering reduce the expected income again. But since I have assumed that $\pi<0.5$, the expected profit function is not defined for a leverage of below 10 .

\subsection{Expected losses}

As shown above, there is a negative relation between the leverage and the default risk of a bank. In other words, the default risk of a bank increases as its leverage falls. However, higher leverage comes with higher losses for a default and, hence, a stronger effect from the default. According to Hellmann et al. (2000), regulation aims to protect the economy from the costs of a banking crisis. In my model, this is consistent with lowering the expected losses for depositors. ${ }^{8}$ Therefore, I focus on this objective.

\footnotetext{
${ }^{8}$ And the government (see Section 3). Kahane (1977), on the other hand, assumes that regulation aims to minimize the probability of default, i.e. without regarding the corresponding loss-given-default (LGD). In my model, a lower default probability is accompanied by a higher LGD. Therefore, Kahane's purpose of regulation would be an unrealistic assumption and would lead to an insufficient regulation.
} 
Proposition 3 For the monopolistic bank with perfectly informed depositors, there is a concave relation between leverage $(f)$ and the expected losses for depositors in which the maximum expected losses occur at a leverage between a leverage of one and the maximum leverage of $f=I / C+1$.

Proof See below.

The expected losses $(E L)$ for depositors are equal to the default probability $(P D=\pi)$ multiplied by the LGD $(L G D=(f-1) C)$. Hence,

$$
E L=\pi(f-1) C=\pi I(1-\pi)\left[1-\sqrt{\frac{\pi P}{(1-P)(1-\pi)}}\right] .
$$

Thus, the expected losses are zero if $f=1$ as well as if $\pi=0$ and, therefore, $f=I / C+1$. In the relevant range, Eq. 20 is a continuous function; and following Proposition 1, there is a negative relation between $f$ and $\pi$. Therefore, there has to be a maximum expected loss $(E L)$ between $f=1$ and $f=I / C+1$.

Hence, Proposition 3 is proven.

The relation between the leverage of the bank and the expected losses for its depositors is illustrated in Fig. 1. This figure is constructed by assuming the parameter values are $C=1$ and $I=50$, the cost function is $k(\pi)=0.01 / \pi$, and the price function $P=1-$ $\sqrt{\pi}$. Therefore, the expected losses increase with leverage until the decrease in the default probability outweighs the increase in leverage, and then the expected losses decrease again. For $f \rightarrow f^{\max }=I / C+1=51$, the expected losses are almost zero. The maximum $E L$ is at a leverage of about 11.5 and, therefore, at a lower leverage than the profit maximizing leverage. Moreover, since I $\pi<0.5$, the expected loss function is not defined for leverage below 10 .

\section{Moral hazard}

Moral hazard emerges when depositors expect the government to bail out a bank in imminent danger of insolvency. Because the government is covering part of the risk, depositors are willing to accept the higher risk of the bank, and the bank has an incentive to increase risk-taking. Since governments are especially likely to bail out systemically important banks, the effect of risk-taking on these banks is expected to be stronger than for non-systemically important banks.

In this section, I examine the effects of (implicit) government guarantees on the leverage and the risk-taking of an unregulated bank. I assume that the bank is systemically important if its total deposits exceed a threshold of $S<I$ or $(f-1) C>S$. Thus, the government will bail out a systemically important bank if it becomes insolvent with the probability $0<\beta<1$. For simplicity, the probability for a bailout is assumed to be zero if the bank is not systemically important.

\subsection{Effects on behavior}

\subsubsection{Behavior of depositors}

In the following, I assume that depositors know whether the bank is systemically important or not, and they know the bailout probability is $\beta$. Hence, for a systemically important bank, 
the probability that depositors will get a positive return $\phi r$ is:

$$
\beta \pi+1-\pi=1-(1-\beta) \pi>1-\pi .
$$

Accordingly, the probability for the negative return $-\phi$ is:

$$
(1-\beta) \pi<\pi \text {. }
$$

By replacing the actual default probability $\pi$ in Eq. 9 with the "moral hazard" default probability $(1-\beta) \pi$, the supply of deposits under moral hazard $\left(\phi^{\prime} I\right)$ is:

$$
\phi^{\prime} I=\left[1-(1-\beta) \pi \frac{1+r}{r}\right] I>\phi I .
$$

Therefore, for a given default risk $\pi$ and interest rate $r$ under moral hazard, depositors are willing to make more deposits than without moral hazard. This in turn means that depositors demand a lower interest rate for a given supply of deposits and a given default risk. Therefore, Eq. 11 can be rewritten as:

$$
r^{\prime}(\beta)=\frac{(1-\beta) \pi I}{(1-(1-\beta) \pi) I-(f-1) C}<r .
$$

Thus, the interest rate $r^{\prime}$ with moral hazard depends negatively on the bailout probability $\beta$. Hence, for a given default probability $\pi$, the interest rate that a systemically important bank has to pay on its deposits is lower than in the benchmark case $(\beta>0)$.

\subsubsection{Behavior of the bank}

Proposition 4 Under implicit government guarantees for a given default probability $\pi$, the leverage of the unregulated monopolistic bank is higher than without guarantees.

Proof See below.

Given the new function for the interest rate reaction (24), the expected profits $\left[E\left(Y^{m h}\right)\right]$ of the bank are now:

$$
E\left(Y^{m h}\right)=(1-\pi)\left[f \frac{1}{P}-(f-1)-\frac{(f-1)(1-\beta) \pi I}{(1-(1-\beta) \pi) I-(f-1) C}\right] C-k(\pi) .
$$

The profit maximizing leverage under moral hazard $\left(f^{m h}\right)$ is given by:

$$
f^{m h}=1+\frac{I}{C}(1-(1-\beta) \pi)\left[1-\sqrt{\frac{(1-\beta) \pi P}{(1-P)(1-(1-\beta) \pi)}}\right] .
$$

Therefore, $f^{m h}$ depends positively on $\beta$. Hence, for a given default probability $(\pi)$, moral hazard leads to higher leverage and higher investment in the risky asset. ${ }^{9}$

Hence, Proposition 4 is proven.

Proposition 5 Under implicit government guarantees, the expected profits of the bank and the optimal default probability are higher than without the guarantee.

\footnotetext{
${ }^{9}$ If this higher investment had an effect on the bond price, moral hazard would also lead to higher asset prices. This effect is demonstrated, for example, by Krugman (1998).
} 
Proof See below.

Given the optimal leverage $f^{m h}$ under moral hazard, the expected profits are:

$$
\begin{array}{r}
E\left(Y^{m h}\right)=\frac{1-\pi}{P} C+\frac{1-\pi}{P} I[1-P-(1-\beta) \pi+2 P(1-\beta) \pi \\
-2 \sqrt{(1-\beta) \pi(1-(1-\beta) \pi) P(1-P)}]-k(\pi) .
\end{array}
$$

Therefore, the only difference relative to benchmark expected profits (17) is that the $\pi$ within the square brackets are multiplied by $(1-\beta)$. As these $\pi$ have a negative effect on the expected profits, this multiplication has a positive effect on the expected profits. As a result, for a given default probability $\pi$, the expected profits are higher with moral hazard than without; hence, the maximum profits also have to be higher than without moral hazard.

A further effect of the multiplication by $(1-\beta)$ is that for a given $\pi$ the derivative of $E\left(Y^{m h}\right)$ with respect to $\pi$ is higher than the derivative of the benchmark $E(Y)$ with respect to $\pi$. Since an optimum requires a concave relation between $\pi$ and the expected profits, it means that the optimal default probability $\pi$ with moral hazard has to be higher than the optimal default probability with the benchmark.

Hence, Proposition 5 is proven.

While moral hazard leads to higher default rates, whether it also leads to higher leverage is not clear. According to Proposition 4, the moral hazard leverage is higher than the benchmark leverage for a given $\pi$. However, the higher default risk with moral hazard has a negative effect on leverage. Whether the positive or negative effect dominates depends on the effect of $\pi$ on $P$.

For illustration, Fig. 2 displays the relation between leverage and expected profits with and without moral hazard. The parameter values are assumed to be $C=1$ and $I=50$, the cost function is $k(\pi)=0.01 / \pi$, and the price function $P=1-\sqrt{\pi}$. The bailout probability $\beta$ is $10 \%$. Thus, in comparison with the benchmark case, the expected profits shift upwards (maximum profits increase) and slightly to the left (lower leverage). The optimal leverage with moral hazard is about 17 and therefore lower than the optimal leverage with the benchmark (18). However, since I have assumed that $\pi<0.5$, the expected profit function is not defined for a leverage of below 12.5 .

With potential government interventions, the bank not only has to consider the lower interest rate with moral hazard but also whether it is more attractive to be systemically important or not. Or, in other words, the bank also has to decide whether it should have leverage of $f \leq S / C+1$ and pay the interest rate $r$ or have leverage of $f^{m h}>S / C+1$ and pay the lower interest rate $r^{m h}$. In the example used for Fig. 2, becoming systemically important is attractive up to a threshold $S$ when $(f-1) C=25$.

\subsection{Effects on expected losses for depositors}

Proposition 6 For a given default probability $\pi$ of the unregulated monopolistic bank, the expected losses on its deposits are higher with implicit government guarantees than without them. The maximum expected loss under implicit government guarantees is obtained at a higher default probability than without them. 


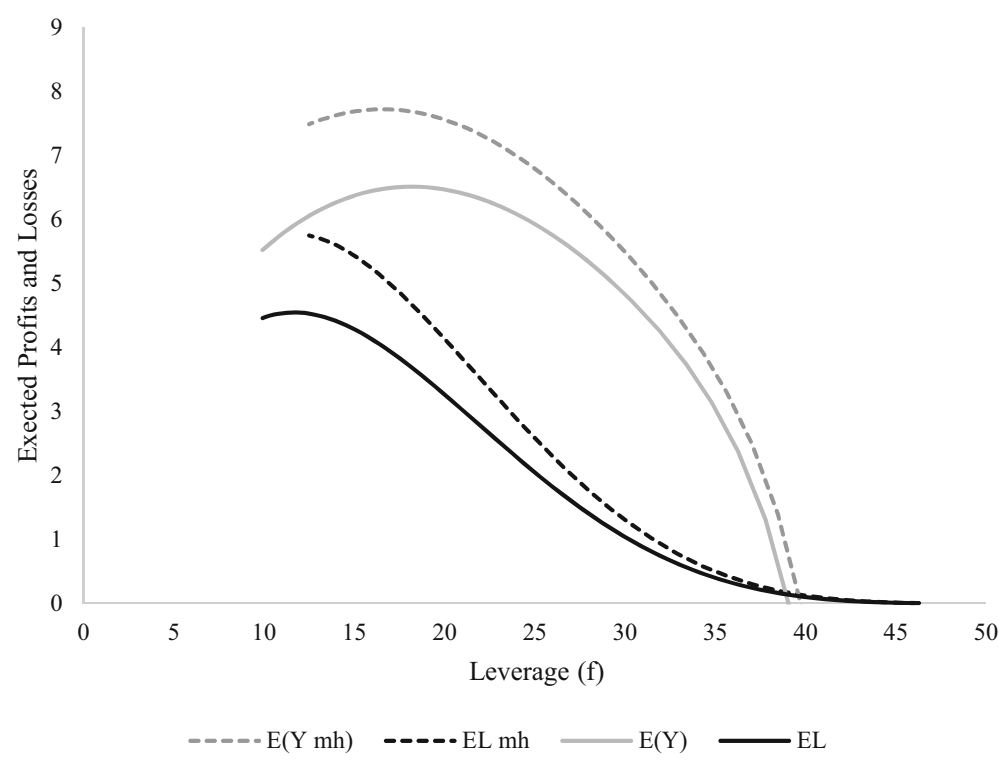

Fig. 2 Relation of leverage and the expected losses $\left(E L^{m h}\right.$ and $\left.E L\right)$ as well as the expected profits $\left(E\left(Y^{m h}\right)\right.$ and $E(Y))$ with and without moral hazard. $P(\pi)=1-\sqrt{\pi}, I=50, C=1, k(\pi)=0.01 / \pi$ and $\beta=0.4$

Under (implicit) government guarantees, the expected direct losses for depositors are reduced because the government with some probability pays in the case of a default. However, depositors are still affected indirectly because the government has to finance the bailout via taxes. Therefore, the aggregated expected losses $\left(E L^{m h}\right)$ for depositors and the government need to be considered:

$$
E L^{m h}=\pi\left(f^{m h}-1\right) C=\pi I(1-(1-\beta) \pi)\left[1-\sqrt{\frac{(1-\beta) \pi P}{(1-P)(1-(1-\beta) \pi)}}\right] .
$$

The direct effect of $\pi$ on expected losses is positive and equal to the direct effect in the benchmark case (20). However, $\pi$ has a negative indirect effect on the expected losses due to the negative effect on leverage. As this negative effect is reduced by the implicit government guarantees (factor $1-\beta$ ), the expected losses are higher for a given $\pi$. In addition, the derivative of $E L^{m h}$ with respect to $\pi$ becomes higher. Since there is a concave relation between $\pi$ and the expected losses, it means that the maximum expected loss under government guarantees is obtained at a higher default probability than without them.

Hence, Proposition 6 is proven.

The effect of moral hazard on the expected losses is displayed in Fig. $2 .{ }^{10}$ In comparison with the benchmark case, the expected losses are inflated and reach their maximum at a

\footnotetext{
${ }^{10}$ The parameter values are $C=1$ and $I=50$, the cost function is $k(\pi)=0.01 / \pi$, and the price function $P=1-\sqrt{\pi}$. The bailout probability $\beta$ is $10 \%$.
} 
slightly lower leverage. However, as $\pi<0.5$, the expected loss function is not defined for a leverage of below 12.5 .

\section{Policy evaluation}

As Section 3 showed, implicit government guarantees for systemically important banks lead to moral hazard that distorts markets and leads to higher risk-taking by the bank and higher expected losses for depositors (and the government). There are basically two ways for policy to deal with this distortion: (a) lower the systemic importance and therefore the likelihood of a government intervention or (b) change bank behavior under moral hazard to achieve a market outcome that better reflects the benchmark case.

In the following, I evaluate different kinds of regulations with regard to their performance in achieving these two policy goals. I look at a pre-Basel kind of leverage restriction, the Basel I and II types of risk-adjusted capital requirement, and the Basel III-inspired mixture of a leverage restriction and a risk-adjusted requirement.

\subsection{Leverage restriction}

Since expected losses are driven by the default risk and the leverage of a bank, an obvious way to deal with the inflated expected losses with moral hazard is to limit the leverage by introducing a restriction:

$$
f \leq \bar{f}
$$

where $\bar{f}$ is the regulatory maximum leverage. If $\bar{f}$ is lower than the optimum leverage of a systemically important bank, then the leverage restriction counteracts the higher leverage relative to the default risk (see Proposition 4). However, since risk-taking is not regulated, the reduction in leverage leads to higher risk-taking (higher $\pi$, see Proposition 1). As a result, distortion of expected losses is not affected and the result is just a different point on the $E L^{m h}$ - line in Fig. 2. In fact, as in our example, expected losses could even increase as a result of the leverage restriction. Hence, the performance of the leverage restriction with regard to the market distortion caused by systemic importance is rather limited.

The performance of the leverage restriction is better when the reduction of systemic importance is considered. I have assumed that a bank is systemically important if its total deposits $((f-1) C)$ exceed the threshold $S$. Hence, if $\bar{f}$ is low enough, then the bank might stop being systemically important. However, this condition means that the bank reacts to the leverage restriction by reducing size and not by increasing capital $(C)$. This option is not directly considered in the model but the bank should have an incentive to increase capital in order to stay systemically important. In fact, banks usually react to tighter capital regulation by a mixture of reducing the size of their balance sheets and raising more capital. Therefore, a leverage restriction can only be successful in reducing systemic importance if it is combined with a restriction on the amount of capital.

\subsection{Risk-adjusted capital requirements}

Because of the adverse effects of a pure leverage restriction on risk-taking, Basel I and especially Basel II introduced risk-adjusted capital requirements. To integrate these requirements into my model, I assume that the capital of the bank $(C)$ has to be higher than its total 
assets $(f C)$ multiplied by the default probability $(\pi)$ and divided by a constant $(\rho)$, but no not-risk-adjusted capital requirement is imposed. Therefore,

$$
\begin{aligned}
C & \geq \frac{1}{\rho} \pi f C \\
\Rightarrow f & \leq \rho \frac{1}{\pi} .
\end{aligned}
$$

Hence, the maximum leverage depends negatively on the default probability. The expected losses under risk-adjusted capital requirements $\left(E L^{r a}\right)$ are given by:

$$
E L^{r a} \leq \pi(f-1) C=\left(\rho-\frac{\rho}{f}\right) C .
$$

Hence, with binding risk-adjusted capital requirements, the expected losses depend positively on the leverage, and the upper limit (for $f \rightarrow \infty$ ) of the expected losses is given by $\rho C$. However, following Proposition 3 for an unregulated bank, there is a concave relation between leverage and the expected losses. This relation means that above a certain leverage, the risk-averse depositors demand a lower default probability than the risk-adjusted capital requirements. As a result, for a bank with high leverage the requirement is not binding. For a bank with very high leverage and low risk, the introduction of risk-adjusted capital requirements does not reduce the adverse effects of moral hazard.

If the risk-adjusted capital requirements are binding, they have the potential to mitigate the effect from moral hazard. However, the bank has different options to react to the requirement. One option is to reduce leverage. In this case, less leverage reduces expected losses for the depositors and the size of the systemic bank. However, the bank could also reduce the default probability and increase leverage to the extent that the requirement is not binding. If this is the case, the regulation does not mitigate the moral hazard of the systemic bank and even provides an incentive to increase leverage and therefore size and systemic importance.

When our simulated example has $C=1, I=50, \beta=10 \%, k(\pi)=0.01 / \pi$, and $P=1-\sqrt{\pi}$; a binding risk-adjusted requirement with $\rho=2$ and $\pi=\rho / f$ leads to an optimal leverage of $24 .{ }^{11}$ As the requirement is binding up to a leverage of roughly 27 , the risk-adjusted requirement for a systemic bank with an unregulated optimal leverage of between 24 and 27 leads to a mitigation of moral hazard and to lower leverage. In my example, the optimal unregulated leverage with moral hazard is about 17 . Hence, the riskadjusted capital requirement can mitigate moral hazard but is likely to increase leverage and systemic importance. ${ }^{12}$

With a far less restrictive $\rho=6$, the regulation is only binding up to a leverage of about 14. Hence, as profit maximizing leverage of an unregulated bank under moral hazard is about 17 , the regulation is not binding and does not mitigate the adverse effects of moral hazard.

Figure 3 displays the expected losses in the benchmark case $(E L)$ under moral hazard $\left(E L^{m h}\right)$ and with risk-adjusted capital requirements $\left(E L^{r a}\right)$. The parameter values are $C=$ $1, I=50, \beta=0.10, k(\pi)=0.01 / \pi, P=1-\sqrt{\pi}$, and $\rho=4$. For low leverage, the risk-adjusted capital requirements significantly reduce the expected losses, and asset risk is even lower than in the benchmark case. With increasing leverage, the expected losses move

\footnotetext{
${ }^{11}$ When I replace $\pi$ in Eq. 25 with $\rho / f$, I get the optimization problem of a systemic bank under binding risk-adjusted capital requirements.

${ }^{12}$ See Begenau (2020).
} 


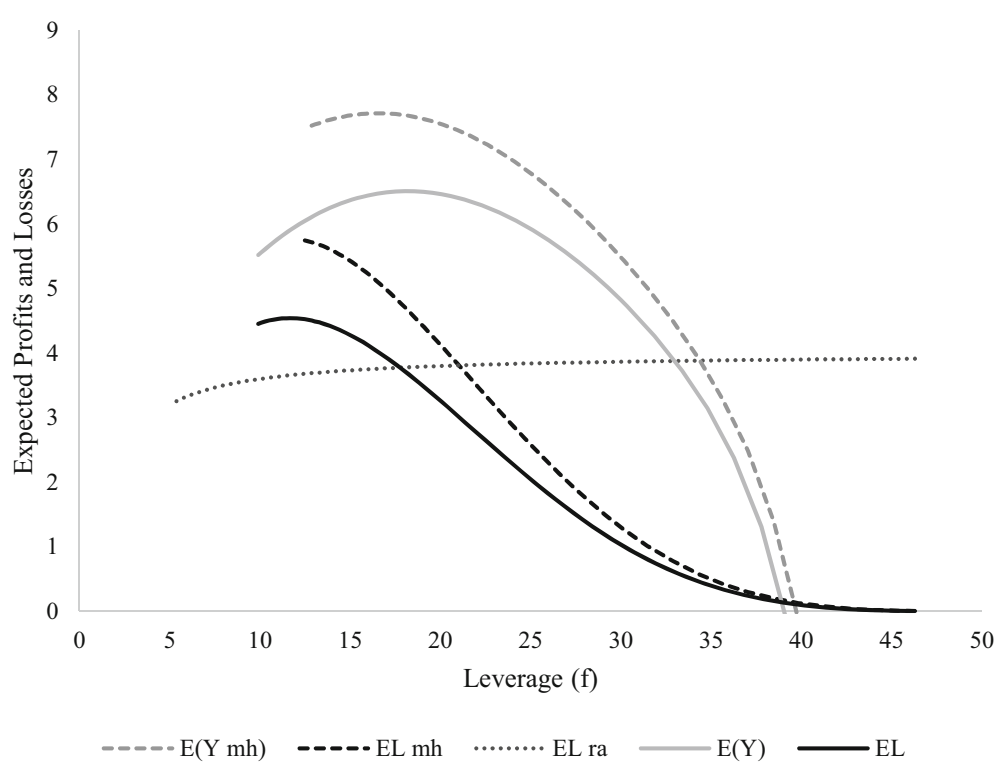

Fig. 3 Relation of leverage and the expected losses $\left(E L, E L^{m h}\right.$, and $\left.E L^{r a}\right)$ as well as the expected profits $\left(E(Y)\right.$ and $\left.E\left(Y^{m h}\right)\right) . C=1, I=50, \beta$ is $10 \% k(\pi)=0.01 / \pi, P=1-\sqrt{\pi}$ and $\rho=2$

to their maximum of $\rho C=4$. At a leverage of about 18 , the expected losses of the regulated systemic bank are equal to the benchmark expected losses. However, the profit maximizing leverage under a binding risk-adjusted requirement is about 19 (not displayed in Fig. 3). Hence, the regulation can slightly mitigate moral hazard, but it leads to higher leverage and therefore systemic importance.

For systemic banks with a leverage of more than 21 , the risk-adjusted capital requirements are not binding. This result is in line with the fact that before the introduction of the leverage restriction under Basel III, some large banks (e.g., Deutsche Bank or UBS) were very highly leveraged but had a relatively high capitalization when compared to their risk-weighted assets. ${ }^{13}$

Another problem with risk-adjusted capital requirements is that the authorities have difficulty in assessing the risk $(\pi)$ correctly. If they underestimate the risk, the expected losses would be much higher than intended.

\subsection{Risk-adjusted capital requirements plus leverage restriction}

To summarize, on the one hand a leverage restriction has the potential to reduce size and therefore the systemic relevance of a bank but does not mitigate moral hazard. The riskadjusted requirements, on the other hand, have the potential to mitigate moral hazard but

\footnotetext{
${ }^{13}$ According to the Swiss National Bank (2011, p. 30, chart 16), the capital-to-asset ratios of major internationally active banks do not increase with higher capital-to-risk-weighted assets. This stability indicates that higher leverage is more or less completely offset by lower risk weights.
} 
are not well suited to reduce systemic importance. Could a combination of both measures lead to better results? Then the minimum of both requirements would be binding:

$$
f \leq \min \left[\rho \frac{1}{\pi} ; \bar{f}\right] .
$$

The introduction of a leverage restriction as a compliment to the risk-adjusted capital requirements in Basel III could force the bank to adjust its leverage and its risk-taking in a way that the risk-adjusted capital requirements become binding. Figure 3 shows that a regulatory maximum leverage of $\bar{f}=18$ not only leads to a lower leverage (compared to 19 in Section 4.2) but also leads to expected losses that are equal to the benchmark's expected losses.

In order to get to this outcome, it is important to have the right balance between both requirements, the risk-adjusted requirements and the leverage restriction. If the risk-adjusted requirements are too lax, adding the leverage restriction may have the size effects as described in Section 4.1. However, if the requirements were too strict, the resulting asset risk would be lower than in the benchmark case. This again would harm the efficiency of the market as well as banks' ability to offer their service. ${ }^{14}$ As long as one has to only deal with a single bank or a very homogeneous set of banks, finding this right balance is feasible. However, if there are many banks with very different business models, finding an appropriate balance could be challenging.

\section{Conclusions}

In this paper, I have examined the effects of implicit government guarantees and capital regulation on the behavior of a bank and on the expected losses for its depositors. In a benchmark model without moral hazard, informational imperfections, and regulatory requirements, the risk-taking of a bank depends negatively on its leverage. The reason is that the bank has to reduce risk in order to attract more affordable deposits from risk-averse depositors. To have extremely high leverage, the bank's assets have to be almost risk free and the expected losses for the depositors have to be almost zero. If, on the other hand, the bank takes very high risks, deposits become very expensive and the bank will finance its investments solely with its own capital. As a result, the expected losses are, again, zero. Starting from a leverage of one, the expected losses for its depositors increase with leverage, but above a certain leverage, the relation reverses.

The introduction of implicit government guarantees does not change the basic relation among leverage, risk-taking, and expected losses. However, with implicit guarantees the disciplining effect of deposits diminishes and a bank may be able to attract more deposits at higher levels of asset risk. As a result, for a given leverage, the bank takes more risk. This level of risk-taking leads to higher expected losses for depositors than in the benchmark case and creates the need for regulation.

Policy measures that aim to reduce the adverse effects of moral hazard are effective only in limited circumstances. Because a simple leverage restriction does not necessarily reduce the expected losses for depositors, it is very likely that the leverage restriction will increase these losses as the bank has an incentive to increase asset risk. With risk-adjusted capital

\footnotetext{
${ }^{14}$ See Van den Heuvel (2008).
} 
requirements, the expected losses for the depositors of a bank with low leverage can be reduced. However, the requirements do not affect a highly leveraged bank with very low asset risk as that bank is more restricted by the disciplining effect of deposits. In such a case, the risk-adjusted requirements do not reduce the adverse effects of moral hazard. But in contrast to the simple leverage restriction, the expected losses do not increase.

The combination of risk-adjusted capital requirements and a leverage restriction - as introduced by Basel III - that are both binding reduces the expected losses. However, a fixed regulation would work only for a very homogenous group of banks. A regulation that varies with bank characteristics would also work, but such a regulation might be very difficult to design and enforce.

Adding a leverage restriction as a complement to risk-weighted requirements is an imperfect reaction to recent banking crises. A major contribution of this paper is to showcase the fragility of the capital regulation under Basel III. Further research should develop instruments to better control systemic importance and the risk-taking of banks.

There are two main shortcomings of this paper. First, the model treats the amount of capital of the bank as given and fixed. Therefore, the model does not capture the effects of an adjustment in the amount of capital on the systemic importance and profits of the bank and the expected losses for depositors. Second, because of the payout structure of its assets, the bank either survives or fails completely. Therefore, the leverage of the bank has no direct effect on its probability of default, which would be more realistic. Nevertheless, this paper is able to explain some very relevant aspects of bank behavior under implicit guarantees, imperfect information, and various kinds of capital regulations.

\section{Appendix: Relationship between risk $\pi$ and bond price $P(\pi)$}

I assume that risk averse bond investors are endowed with an initial wealth $Z$ and maximize their expected utility from consumption in the first and the second period by choosing how much they save $(X)$ and how they invest these savings. They invest the amount $\gamma X$ in the bond and $(1-\gamma) X$ in the safe asset. Hence, the maximization problem of the investors is given by:

$$
E U=U[Z-X]+\delta \pi U[(1-\gamma) X]+\delta(1-\pi) U[(\gamma / P+1-\gamma) X],
$$

where $U[]$ is the utility function of the investors, and $\delta$ is the discount factor. Maximization leads to:

$$
\pi U^{\prime}[(1-\gamma) X]=(1-\pi) \frac{1-P}{P} U^{\prime}[(\gamma / P+1-\gamma) X]
$$

I further assume that the number of investors is equal to the number of bonds. Hence, the price of one bond is equal to the bond investments of one investor $(P=\gamma X)$, and we get:

$$
\pi \gamma X U^{\prime}[(1-\gamma) X]=(1-\pi)(1-\gamma X) U^{\prime}[1+(1-\gamma) X] .
$$


In order to calculate the effect of $\pi$ on $\gamma$ (and therefore on $P$ ), we calculate the total differential of the above equation:

$$
\begin{array}{r}
\left\{\pi X U^{\prime}[(1-\gamma) X]-\pi \gamma X^{2} U^{\prime \prime}[(1-\gamma) X]\right\} d \gamma+\gamma X U^{\prime}[(1-\gamma) X] d \pi \\
=\left\{-(1-\pi) X U^{\prime}[1+(1-\gamma) X]-(1-\pi)(1-\gamma X) X U^{\prime \prime}[1+(1-\gamma) X]\right\} d \gamma \\
-(1-\gamma X) U^{\prime}[1+(1-\gamma) X] d \pi .
\end{array}
$$

Using condition (35) and $R_{a}[]=-U^{\prime \prime}[] / U^{\prime}[]$ as a measure of absolute risk aversion, we can write:

$$
d \gamma(1-\pi)\left\{1+(1-P) P\left(R_{a}[(1-\gamma) X]-R_{a}[1+(1-\gamma) X]\right)\right\}=-d \pi \frac{(1-P) \gamma}{\pi} .
$$

Since $d P / d \pi=X d \gamma / d \pi$ we get:

$$
\frac{d P}{d \pi}\left\{1+(1-P) P\left(R_{a}[(1-\gamma) X]-R_{a}[1+(1-\gamma) X]\right)\right\}=-\frac{(1-P) P}{(1-\pi) \pi} .
$$

Hence, for CARA utility $\left(R_{a}[1]=R_{a}[2]\right)$, the term in brackets is equal to one and for DARA utility $\left(R_{a}[1]>R_{a}[2]\right.$ if [1] $<$ [2]), the term is larger than one. Therefore, if we assume CARA or DARA utility functions, which is standard, we get:

$$
\frac{d P}{d \pi} \geq-\frac{(1-P) P}{(1-\pi) \pi}
$$

As an illustration, with a logarithmic utility function and $X=1$, condition (35) is:

$$
\frac{\pi \gamma}{1-\gamma}=\frac{(1-\pi)(1-\gamma)}{2-\gamma}
$$

As a result, $\gamma=1-\sqrt{\pi}$ and since $P=\gamma X$ :

$$
P=1-\sqrt{\pi}
$$

Acknowledgements I would like to thank Mark Carey and two anonymous referees for their helpful comments and suggestions.

Funding Open Access funding enabled and organized by Projekt DEAL.

Open Access This article is licensed under a Creative Commons Attribution 4.0 International License, which permits use, sharing, adaptation, distribution and reproduction in any medium or format, as long as you give appropriate credit to the original author(s) and the source, provide a link to the Creative Commons licence, and indicate if changes were made. The images or other third party material in this article are included in the article's Creative Commons licence, unless indicated otherwise in a credit line to the material. If material is not included in the article's Creative Commons licence and your intended use is not permitted by statutory regulation or exceeds the permitted use, you will need to obtain permission directly from the copyright holder. To view a copy of this licence, visit http://creativecommons.org/licenses/by/4.0/.

\section{References}

Alexander GJ, Baptista AM (2017) Bank capital regulation of trading portfolios: an assessment of the Basel framework. J Money Credit Bank 49(4):603-634 
Ashcraft AB (2008) Does the market discipline banks? new evidence from regulatory capital mix. J Financ Intermed 7:543-561

Basel Committee on Banking Supervision (2014) Basel III leverage ratio framework and disclosure requirements. January 2014

Begenau J (2020) Capital requirements, risk choice, and liquidity provision in a business cycle model. J Financ Econ 136(2):355-378

Behr P, Schmidt R, Xie R (2010) Market structure, capital regulation and bank risk taking. J Financ Serv Res 37:131-158

Berger A, DeYoung R, Flannery M, Lee D, Öztekin Ö (2008) How do large banking organizations manage their capital ratios? J Financ Serv Res 34:124-149

Bernanke B, Gertler M, Gilchrist S (1999) The financial accelerator in a quantitative business cycle framework. In: Taylor JB, Woodford M (eds) Handbook of macroeconomics, vol 1. Elsevier, pp 1341-1393

Bhattacharya S, Goodhart CAE, Tsomocos DP, Vardoulakis AP (2015) A reconsideration of Minsky's financial instability hypothesis. J Money Credit Bank 47(5):931-973

Blum J (1999) Do capital adequacy requirements reduce risks in Banking? J Bank Finance 23:755-771

Boissay F, Collard F, Smets F (2016) Booms and banking crises. J Polit Econ 2124(2):489-538

Calomiris CW, Kahn CM (1991) The role of demandable debt in structuring optimal banking arrangements. Am Econ Rev 81(3):497-513

Clerc L, Derviz A, Mendicino C, Moyen S, Nikolov K, Stracca L, Suarez J, Vardoulakis AP (2015) Capital regulation in a macroeconomic model with three layers of default. ECB Working Paper, No. 1827

Furlong FT, Keeley MC (1989) Capital regulation and bank risk-taking: a note. J Bank Finance 13:883-891

Geanakoplos J (2010) The leverage cycle. NBER Macroecon Annu 24(1):1-66

Harding J, Liang X, Ross S (2013) Bank capital requirements, capital structure and regulation. J Financ Serv Res 43:127-148

Hellmann TF, Murdock KC, Stiglitz JE (2000) Liberalization, moral hazard in banking, and prudential regulation: are capital requirements enough? Am Econ Rev 90(1):147-165

Hott C (2015) A model of mortgage losses and its applications for macroprudential instruments. J Financial Stab 16:183-194

Kahane Y (1977) Capital adequacy and the regulation of financial intermediaries. J Bank Finance 1:207-218

Kiema I, Jokivuolle E (2014) Does a leverage ratio requirement increase bank stability? J Bank Finance 39:240-254

Kim D, Santomero AM (1988) Risk in banking and capital regulation. J Finance 43(5):1219-1233

Koehn M, Santomero AM (1980) Regulation of Bank Capital and Portfolio Risk. J Financ 35(3):1235-1244

Krugman P (1998) What happened to Asia? MIT Mimeo

Rochet J-C (1992) Capital requirements and the behavior of commercial banks. Eur Econ Rev 36:1137-1178

Schliephake E (2016) Capital regulation and competition as a moderator for banking stability. J Money Credit Bank 48(8):1787-1814

Swiss National Bank (2011) Financial stability report 36:1137-1178

Van den Heuvel S (2008) The welfare cost of bank capital requirements. J Monet Econ 55(2):298-320

VanHoose D (2007) Theories of bank behavior under capital regulation. J Bank Finance 31:3680-3697

Wu H-M, Zhao Y (2016) Optimal leverage ratio and capital requirements with limited regulatory power. Eur Finan Rev 20:2125-2150

Publisher's Note Springer Nature remains neutral with regard to jurisdictional claims in published maps and institutional affiliations. 